\title{
FORMAÇÃO CONTINUADA DO PROFESSOR DO ENSINO MÉDIO INTEGRADO: CONCEPÇÕES E IMPORTÂNCIA
}

\author{
Claudia Maria Bezerra da Silva*, Edlamar Oliveira dos Santos \\ *E-mail: claudiambezerra@yahoo.com.br \\ Universidade Federal de Pernambuco, \\ Instituto Federal de Educação, Ciência e Tecnologia de Pernambuco, Brasil \\ DOI: $10.15628 /$ rbept.2020.9281 \\ Artigo submetido em dez/2019 e aceito em jan/2020
}

\begin{abstract}
RESUMO
O presente artigo tem a finalidade de analisar as concepções e a importância da formação continuada para o trabalho do professor do ensino médio integrado. Buscou-se em Moura (2014), Ramos (2008), Nóvoa (2002), Imbernón (2011), entre outros, as bases teóricas para o estudo. A coleta de dados ocorreu por meio da aplicação de questionários e realização de entrevistas semiestruturadas. Os achados da pesquisa sugerem que os sujeitos reconhecem a formação continuada como importante para o trabalho docente, tendo em vista que permite atualização dos conhecimentos, melhoria da prática e espaço para socialização de experiências. No que diz respeito às expectativas para formação continuada, foram indicadas necessidades relacionadas aos conteúdos, local da formação, metodologia e perfil do formador.
\end{abstract}

Palavras-chave: Formação Continuada do Professor. Ensino Médio Integrado. Educação Profissional e Tecnológica.

\section{TEACHER CONTINUING EDUCATION OF INTEGRATED HIGH SCHOOL: CONCEPTIONS AND IMPORTANCE}

\begin{abstract}
This article had as purpose to analyze the conceptions and importance of continuing education for the work of the teacher of Integrated High School. The theoretical bases for the study were searched at Moura (2014), Ramos (2008), Nóvoa (2002), Imbernón (2011), among others. Data collection was carried out through the application of questionnaires and semistructured interviews. The research findings suggest that the participants recognize the continuous formation as important for the work of the teacher, considering that it allows updating of knowledge, improvement of practice and space for socialization of experiences. Regarding the expectations for continuing education, needs were indicated for the training process that focused on the contents, the place to be developed, the methodology and the trainer.
\end{abstract}

Keywords: Teacher Continuing Education. Integrated High School. Professional and Technological Education. 


\section{INTRODUÇÃO}

As discussões envolvendo a formação de professores para a Educação Profissional e Tecnológica (EPT) vêm ganhando espaço entre educadores e pesquisadores. Ocorre que as constantes mudanças no mundo do trabalho exigem cada vez mais dos alunos egressos dessa modalidade e, como consequência, aos professores fica a necessidade de refletir que já não cabe ter apenas os conhecimentos relativos à dimensão técnica que resultam no treinamento para desenvolver uma atividade laboral.

E quando nos referimos ao ensino médio integrado (EMI), que articula a formação profissional à educação básica propondo a integração de conteúdos para construção de conhecimentos, o saber estritamente técnico ou fragmentado perde ainda mais espaço. No entanto, conforme o pensamento de Moura (2014), nem os professores bacharéis, tecnólogos e licenciados têm formação para atuar na modalidade, algo ideal para compreender os princípios da relação existente entre educação e trabalho.

Com isso, tomamos como objetivo geral deste estudo analisar as concepções e a importância da formação continuada para o trabalho do professor do ensino médio integrado. Para tanto, desenvolvemos o tema por meio da revisão da literatura e análise de documentos e, como instrumentos de pesquisa, utilizamos a aplicação de questionários e realização de entrevistas semiestruturadas com professores e pedagogos do Instituto Federal de Educação, Ciência e Tecnologia de Pernambuco (IFPE)/Campus Recife.

O referencial utilizado para fundamentar as discussões aqui apresentadas pauta-se em estudiosos que se dedicam à investigação e produção teórica relacionada à formação continuada do professor e sobre a EPT, como: Moura (2013, 2014), Ramos (2008, 2017), Machado (2008), Nóvoa (2002), Imbernón (2011), Candau (2001), entre outros.

Para melhor localizar o leitor, estruturamos o artigo da seguinte forma: a seção Integração do ensino médio com a educação profissional e tecnológica aborda os sentidos da integração entre educação e formação para trabalho; $A$ formação continuada do professor apresenta a importância da formação continuada para o trabalho docente; Em Concepções para formação do professor da educação profissional e tecnológica estão concepções de formação para os professores que atuam na modalidade. Em seguida, o espaço está destinado à apresentação do percurso metodológico da pesquisa e a análise dos dados. E, por fim, estão as considerações finais.

\section{INTEGRAÇÃO DO ENSINO MÉDIO COM A EDUCAÇÃO PROFISSIONAL E TECNOLÓGICA}

A formação ofertada no EMI é definida por alguns autores (Ciavatta, 2005; Frigotto, 2005; Ramos, 2008, 2017; Saviani, 2007) como formação integrada, omnilateral, politécnica ou tecnológica. É uma formação com entendimento que a política assistencialista ou mesmo linear ajustamento às demandas do mercado de trabalho tende a ser ultrapassada, dando espaço a 
uma importante estratégia para que todos os cidadãos, independente de classe social, tenham efetivo acesso às conquistas científicas e tecnológicas da sociedade. Nessa perspectiva, a finalidade da profissionalização não teria fim em si mesmo, muito menos se pautaria pelos interesses do mercado, mas se constitui numa possibilidade a mais para o sujeito construir seu projeto de vida.

Ciavatta (2005) afirma que os termos formação integrada, formação politécnica e educação tecnológica buscam responder às necessidades do mundo do trabalho permeado pela presença da ciência e da tecnologia como forças produtivas e geradoras de valores e fontes de riqueza. Para a autora, o que se busca é garantir "[...] o direito a uma formação completa para a leitura do mundo e para a atuação como cidadão pertencente a um país, integrado dignamente à sua sociedade política." (CIAVATTA, 2005, p. 2-3).

O EMI seria uma base unitária que respeita a diversidade da realidade social, oferecendo aos alunos a formação básica e profissional na qual não basta aprender o conhecimento técnico operacional e apenas saber fazer. É necessário ter a compreensão global do processo e da tecnologia que executa para saber o porquê de fazer uma atividade de determinada forma.

Ramos (2008) aponta como pilares da educação integrada uma escola não dual, mas sim que seja unitária, garantindo a todos o direito ao conhecimento; e uma formação politécnica, que possibilite o acesso à cultura, à ciência e ao trabalho por meio da educação básica e profissional. Isso significa "[...] uma educação que possibilita a compreensão dos princípios científico-tecnológicos e históricos da produção moderna, de modo a orientar os estudantes à realização de múltiplas escolhas." (RAMOS, 2008, p.3).

$\mathrm{Na}$ formação no EMI, a escola enquanto instituição que constrói, sistematiza e socializa o conhecimento assume a tarefa de contextualizar as demandas da nova ordem econômica e social com as práticas exercidas em seu interior, impulsionando o desenvolvimento educacional e socioeconômico do país. Para isso, algumas mudanças no currículo e na prática dos professores são necessárias, na intenção de ter a unidade entre teoria e prática, proporcionar a compreensão global do conhecimento, considerar o trabalho como princípio educativo e adotar práticas interdisciplinares. Isso implica a necessidade de ações de formação continuada para os professores que contribuam para a construção de um EMI que ofereça, de fato, a formação básica integrada à profissional.

\section{A FORMAÇÃO CONTINUADA DO PROFESSOR}

A formação continuada configura-se como um processo com conotação de evolução e continuidade, valorizada em virtude dos múltiplos e novos desafios do mundo contemporâneo que solicita dos professores novas práticas para a construção de conhecimentos.

No entanto, percebemos alguns exemplos que enfatizam apenas a reciclagem dos professores, que Candau (2001) nomeia como "clássica", pautados na realização de atividades específicas como cursos, aperfeiçoamento e encontros em um local distinto do contexto de trabalho. 
São casos em que a formação docente é reduzida ao mero processo de atualização para apresentar novas metodologias, técnicas ou implantar projetos, desconsiderando a realidade de trabalho do professor e com uma rigidez como se fossem a solução para todas as questões pertinentes ao processo de ensino-aprendizagem.

São os modelos de formação continuada nos quais as situações problemáticas são apenas instrucionais, com o professor se convertendo, para Imbernón (2011), em ferramenta mecânica de reprodução, o que pode provocar "[...] uma alienação profissional, uma desprofissionalização, que tem como consequências a espera de que as soluções venham dos 'especialistas'[...]." (IMBERNÓN, 2011, p. 55, grifos do autor).

A realidade e os saberes do professor são, portanto, desconsiderados para adotar métodos prontos elaborados por pessoas de fora que, muitas vezes, desconhecem as especificidades do contexto escolar do grupo em formação.

Já a formação continuada que possibilita a construção a partir dos próprios desafios e coloca o professor como sujeito do processo, permite a troca de experiências, dinâmicas reflexivas e a construção de conhecimentos, se caracterizando por uma lógica de ação na qual formação e prática se articulam por um problema real.

Para Imbernón (2011), é possível abandonar a ideia obsoleta de que a formação continuada é a atualização científica, didática e psicopedagógica, para adotar o conceito que consiste em recompor o equilíbrio entre teoria $e$ prática, atribuindo ao professor um modelo formativo mais reflexivo e que contemple um trabalho em equipe desenvolvido no contexto.

Nessa premissa, a prática docente se associa à compreensão de que o ensino acontece num espaço no qual as pessoas, o tempo, o conhecimento e - lugar têm peculiaridades que a formação continuada pode potencializar, sendo possível a valorização dos saberes do professor, que se apoiam no trabalho cotidiano e no conhecimento do meio.

Podemos dizer, diante das proposições apresentadas, que a valorização do conhecimento docente e a formação desenvolvida na escola, ambiente legítimo em que se desenvolve o processo educativo, permitem que a formação continuada não seja apenas uma mera transmissão de técnicas prontas, adquirindo maior efetividade por considerar as questões contextuais e a prática do professor.

\section{CONCEPÇÕES PARA FORMAÇÃO DO PROFESSOR DA EDUCAÇÃO PROFISSIONAL E TECNOLÓGICA}

O professor que atua no EMI encontra o desafio de uma modalidade na qual é necessário estabelecer as conexões entre a formação para o ensino médio e para o trabalho. Em virtude disso, torna-se necessário refletir sobre as perspectivas de formação docente, almejando a formação integral do aluno. 
A partir de um levantamento nos últimos editais das seleções para professor do IFPE - Edital no 44, de 25 de março 2014; Edital oㅡ 125, de 29 de agosto de 2016; e Edital ํo 67, de 14 de junho de 2017 -, constata-se que a titulação exigida para o ingresso de docentes na Instituição é de graduações em licenciatura, bacharelado ou tecnológico, com os licenciados em formações como História, Geografia, Português, Inglês e Educação Física indicados para as disciplinas que fazem parte da formação geral; e os bacharéis e tecnólogos com formações como Engenharia, Contabilidade, Arquitetura, Eletrônica e Logística, para as disciplinas da formação profissional. (IFPE, 2014; 2016; 2017).

Portanto, são dois perfis atuando no IFPE: o primeiro, de profissionais bacharéis e tecnólogos que possivelmente não receberam na graduação a formação para a docência, mas sim voltada para as demandas do mercado, indo de encontro à proposta do EMI. A esses professores, uma prática que considere a formação integral do aluno, deixando de lado os interesses do capital, necessita de suporte teórico-prático das discussões e saberes relacionados aos processos educativos.

O segundo perfil é o de professores licenciados, mas que possivelmente não tiveram em seus currículos de formação inicial estudos referentes ao trabalho e educação, tendo em vista que foram formados:

\begin{abstract}
para atuar no ensino de Matemática, de Química, de Geografia, de História etc. destinado a estudantes do ensino fundamental ou médio, o que é muito diferente de atuar, mesmo nessas disciplinas, em cursos cujo fim é a formação técnica de nível médio, principalmente, o ensino médio integrado à educação profissional. (MOURA, 2014, p. 88).
\end{abstract}

Essas são diferenças na estrutura organizacional dos cursos de formação inicial que podem representar desafios para a prática docente, sobretudo quando se reflete sobre as necessidades e demandas da modalidade, que requerem não apenas conhecimento disciplinar, mas também o diálogo com 0 mundo do trabalho, práticas pedagógicas interdisciplinares e contextualizadas, perspectiva de emancipação do educando, trabalho como princípio educativo e interação com a tecnologia, ciência e cultura.

Nessa perspectiva, devem ser desenvolvidas ações de formação de professores que não sejam apenas uma forma secundária e emergencial. No entanto, ao longo dos anos houve uma sequência de Leis, portarias, pareceres, decretos e resoluções que instituíram, como exemplos, curso de aperfeiçoamento de professores do Ensino Industrial, cursos especiais de educação técnica para habilitar professores para disciplinas do Ensino Técnico, cursos emergenciais para complementação pedagógica e licenciatura visando à formação do professor, todos caracterizados pela descontinuidade. (MACHADO, 2008).

Já no contexto atual, existem ofertas de formação docente, como programas especiais, cursos de pós-graduação e formação a distância, mas são "[...] muito reduzidas considerando o potencial de demanda e nem sempre atendem a todos os perfis de entrada dos candidatos." (MACHADO, 2008, p. 14). 
Considerando a relevância de proporcionar aos atuais e futuros professores 0 acesso aos conhecimentos necessários ao exercício da docência na EPT, Moura (2014) advoga em favor de uma formação que privilegie o humano, de modo que possa assumir uma atitude problematizadora e mediadora no processo de ensino-aprendizagem, combatendo práticas que visam apenas as relações de mercado e o fortalecimento da economia. O autor oferece subsídios importantes, como três núcleos estruturantes relacionados aos conhecimentos que devem estar presentes em qualquer possibilidade formativa do professor, seja na formação inicial ou continuada. São eles:
a) área de conhecimentos específicos;
b) formação didático-político-pedagógica;
c) diálogo constante entre ambas e dessas com a sociedade em geral e, em particular, com o mundo do trabalho. (MOURA, 2014, p. 94).

O primeiro núcleo, na área de conhecimentos específicos, são aqueles adquiridos na graduação e que têm aprofundamento ao longo da formação, pois aos professores "[...] importa compreender que só se pode ensinar o que se domina em profundidade. Portanto, o professor tem que ter competência técnica sobre sua disciplina/área [...]." (MOURA, 2014, p. 95).

Mas ter apenas o conhecimento específico da disciplina que leciona, apesar de necessário e imprescindível, não é suficiente para a docência na perspectiva aqui discutida. Dessa forma, o segundo núcleo refere-se à formação didático-político-pedagógica que, de acordo com Moura (2014, p. 98), deve contemplar:

[...] as relações entre estado, sociedade, ciência, tecnologia, trabalho, cultura, ser humano e educação; políticas e história da educação brasileira e, mais especificamente, a da educação profissional; a discussão relativa à função social da educação em geral, da EP e de cada instituição em particular; a relação entre trabalho e educação; relações entre currículo, educação, cultura, tecnologia e sociedade; currículo integrado; organização e planejamento da prática pedagógica na educação profissional; avaliação do processo de ensino-aprendizagem na educação profissional; concepção de formação que se sustente numa base humanista; concepção de docência que impregne a prática desse profissional quando sua atuação se dá no mundo do trabalho; a profissionalização do docente da EP: formação inicial e continuada, carreira, remuneração e condições de trabalho; desenvolvimento local/regional que considere os aspectos sociais, culturais, políticos e econômicos.

Esses dois primeiros núcleos são relevantes, pois abordam a necessidade de aprofundamento na área de atuação do professor e abrange as questões que circunscrevem a EPT. Disso decorre o terceiro núcleo, que é o diálogo constante entre os conhecimentos específicos e a formação didático-político-pedagógica com a sociedade e com o mundo do trabalho, sendo fundamental para a integração dos saberes, já que as disciplinas e conhecimentos não estão isolados, a "[...] separação é feita por razões didáticas e, pelas mesmas razões, deve-se buscar a recomposição da totalidade." (MOURA, 2014, p. 95). 
Considerar esses elementos na formação do professor pode permitir uma prática pedagógica capaz de contextualizar os saberes com problemas complexos e reais, tendo em vista a íntima relação entre os conhecimentos escolares e a vida profissional, social e cultural, desenvolvendo no aluno a compreensão da realidade.

Moura (2014) também defende que a formação do docente da EPT deve garantir o princípio de pesquisador como sendo fundamental quando o que se deseja é formar professores que não sejam meros aplicadores de conhecimentos, materiais didáticos e experimentos produzidos por especialistas.

Essa perspectiva pode contribuir para que 0 professor planeje e execute sua prática a partir dos próprios conhecimentos e da realidade, trabalhando os conteúdos de forma a atribuir significado e, inclusive, produzir os próprios materiais, promovendo uma atitude de autonomia intelectual diante dos desafios da prática educativa.

Esses são elementos para a formação de professores que considera a compreensão acerca das bases conceituais da EPT e as suas relações, cujo fundamento está na concepção da formação omnilateral do aluno. O que se busca é proporcionar, independente da formação - licenciado, bacharel ou tecnólogo -, uma maior aproximação, reconhecimento e pertencimento do docente com a modalidade em que atua.

\section{PERCURSO METODOLÓGICO DA PESQUISA}

Fundamentado no método dialético e com abordagem qualitativa, o estudo teve a construção teórica realizada por meio de revisão da literatura e análise de documentos, o que propiciou novos conhecimentos e aprofundamento do objeto de estudo.

No tocante à pesquisa de campo, foi realizada no IFPE/Campus Recife com 5 pedagogas e 63 professores. Para escolha dos sujeitos, o critério estabelecido com relação aos professores, foi o de lecionar nos cursos da EMI do Campus, englobando assim, os docentes das disciplinas da formação geral e profissional dos cursos de: Edificações, Eletrônica, Eletrotécnica, Mecânica, Química, Saneamento e Segurança no Trabalho. Já com as pedagogas, o critério foi 0 de acompanhar 0 processo de ensinoaprendizagem nos cursos do EMI na Instituição.

Com relação à formação inicial dos professores, participaram 33 bacharéis, 18 licenciados, 11 que tinham duas graduações e 1 que era tecnólogo, o que proporcionou o enriquecimento da pesquisa, tendo em vista que conta com as mais diversas compreensões em relação ao EMI.

Chamou a atenção o significativo número de bacharéis e o tecnólogo, que juntos totalizam $53,97 \%$ dos professores, remetendo à formação continuada a necessidade de trabalhar conteúdos didático-políticopedagógicos, conforme nos traz Moura (2014), para oferecer um suporte teórico-prático das discussões e saberes relacionados ao processo educativo como currículo, metodologias de ensino, instrumentos de avaliação, formação 
no EMI para o trabalho e relação com os alunos. Isso se faz importante tendo em vista que a esses professores coube inicialmente uma formação com característica técnica, voltada para as demandas do mercado, indo de encontro à proposta do EMI.

A coleta de dados ocorreu por meio da aplicação de questionários e entrevistas semiestruturadas, que abordaram a formação acadêmica, experiência profissional e a importância e desenvolvimento da formação continuada. A todos os participantes foi apresentado o Termo de Consentimento Livre e Esclarecido com informações sobre a pesquisa e compromisso em zelar pela privacidade e sigilo dos dados, assegurando o princípio ético.

A análise e interpretação dos dados procurou dar significado às respostas, vinculando aos objetivos propostos e ao tema. Para tanto, foram categorizados e submetidos à análise de conteúdo que é um conjunto de técnicas "[...] marcado por uma grande disparidade de formas e adaptável a um campo de aplicação muito vasto: as comunicações." (BARDIN, 2016, p. 37).

Nessa perspectiva, foi realizada a tabulação e sistematização das transcrições das entrevistas semiestruturadas e dos questionários. Em seguida, os dados foram categorizados através da utilização de uma frase em que foi possível fazer emergir do texto uma unidade de significação com base na referência da pesquisa, consistindo em um momento essencial e de reflexão crítica. Isso foi necessário tendo em vista que espera-se na análise de conteúdo que os resultados devem ir além de uma simples descrição dos conteúdos da mensagem, mas também interpretá-los a fim de garantir sua pertinência teórica.

\section{FORMAÇÃO CONTINUADA NO CONTEXTO DO ENSINO MÉDIO INTEGRADO}

Nesta seção, apresentamos a análise dos dados, iniciando com os coletados por meio dos questionários com professores e pedagogos que trazem a compreensão sobre a importância da formação continuada para 0 trabalho docente. Em seguida, estão as expectativas para formação continuada, obtidas por meio das entrevistas semiestruturadas com os professores.

\section{1 COMPREENSÃO SOBRE A FORMAÇÃO CONTINUADA}

A reflexão caminha a fim de identificar qual a importância da formação continuada para o trabalho do professor. Os dados remetem, então, a: atualização docente, melhoria da prática e socialização de experiências.

A formação continuada como importante para a atualização docente foi indicada pelos participantes como uma possibilidade para promover novos estudos e ressignificar os conhecimentos. Isso significa considerar que apenas a formação inicial não basta para a prática em sala de aula, mas é necessária a contínua atualização, sobretudo, quando está alinhada aos interesses da realidade da qual faz parte, atendendo às próprias demandas. 
Como afirma Nóvoa (2002), a formação contínua deve estimular no professor a apropriação dos saberes dos quais são portadores, no quadro de uma autonomia contextualizada e interativa, que lhes permita reconstruir os sentidos da sua ação profissional.

A atualização docente foi ressaltada também como uma possibilidade de obter conhecimentos relacionados ao processo de ensino-aprendizagem e da docência. Seria a atualização dos conhecimentos pedagógicos que, conforme Tardif (2014), se apresentam como doutrinas ou concepções provenientes de reflexões sobre a prática educativa, que conduzem a orientação do trabalho do professor.

Assim, esses conhecimentos estão relacionados à atividade em sala de aula, atribuindo à formação continuada a configuração de um processo educativo constante e necessário para a prática docente, podendo se refletir na melhoria da prática, que também surgiu nos dados, tendo em vista promover o processo de ensino-aprendizagem cada vez mais efetivo. Essa questão nos remete à García (1999), quando fala sobre desenvolvimento profissional, entendendo como o conjunto de processos e estratégias que facilitam a reflexão dos professores sobre a prática, contribuindo para gerar conhecimento e ser capaz de aprender com a própria experiência.

Nesse contexto, o desenvolvimento profissional do professor é refletido no desenvolvimento do ensino. Ou seja, o processo de formação docente está relacionado ao possível aperfeiçoamento das competências para ensinar. A formação contínua não seria, portanto, apenas o aperfeiçoamento, a qualificação ou a progressão na carreira docente, mas "[...] joga-se também aqui a possibilidade de uma mudança educativa coerente e inovadora." (NÓVOA, 2002 p. 62). Assim, os conhecimentos adquiridos nas ações de formação continuada podem ser refletidos na qualidade do ensino ministrado nas escolas, produzindo alterações positivas no trabalho do professor.

A formação continuada também é associada à socialização de experiências e, consequentemente, responsável por promover a interação entre os pares, oportunizando troca de conhecimentos e aprendizado. Nesse sentido, a formação continuada que propicia a socialização pode conduzir a uma produção pelos próprios professores de saberes reflexivos e pertinentes, já que a troca de experiências consolida espaços nos quais cada professor é chamado a desempenhar, simultaneamente, o papel de formador e de formando. (NÓVOA, 2002).

Para Imbernón (2011), a formação permanente deve desenvolver processos de aprendizagem colaborativa, com troca de experiências para que possa tornar possível a atualização em todos os campos de intervenção educativa e aumentar a comunicação entre os professores.

A interação com os pares oportuniza a reflexão sobre a realidade, enriquecendo 0 ato de educar, pois promove espaços para troca de experiências e saberes, consolidando uma formação mútua que considera a prática apoiada no conhecimento teórico e experiencial. $E$, quando remetemos às especificidades do professor do EMI, essa questão pode contribuir, conforme Moura (2014), para a aproximação das diferentes trajetórias dos licenciados, bacharéis e tecnólogos, possibilitando o trabalho 
coletivo e as práticas efetivamente integradoras, rompendo com a dualidade entre o professor das disciplinas da educação geral e das disciplinas da educação profissional.

A formação continuada dos professores é decisiva para que a democratização da EPT se efetive com qualidade social, produção de conhecimentos e valorização docente, podendo resultar em uma formação do aluno que atenda, de fato, aos princípios do EMI.

\section{2 EXPECTATIVAS PARA FORMAÇÃO CONTINUADA DOS PROFESSORES DO ENSINO MÉDIO INTEGRADO}

No que diz respeito às expectativas para formação continuada, a reflexão caminhou no sentido de focalizar os aspectos referentes aos conteúdos, o local para ser desenvolvida, a metodologia e o formador. Os dados apontam para formação que aborde conteúdos didático-pedagógicos e conteúdos específicos, tanto aconteça na instituição quanto fora dela, permita a troca de experiência, associe teoria e prática e, finalmente, que seja desenvolvida com mediador experiente.

Iniciamos com os dados nos quais os professores indicam a necessidade de obter um suporte dos saberes pertinentes à docência, como uma formação que aborde conteúdos didático-pedagógicos. Essa questão pode ter surgido pelo fato de ter engenheiros, contadores, administradores e outros bacharéis e tecnólogos que exercem a docência sem que tenham formação para tal, apontando para o reconhecimento de que no processo de ensino-aprendizagem não cabe apenas o domínio relativo à dimensão técnica, mas também é importante saber como didaticamente o conhecimento pode ser construído em sala de aula. Portanto, ao professor é importante saber como vai transpor os conteúdos para situações educativas, devendo para isso:

conhecer os modos como se dá a aprendizagem [...], as formas de organizar o processo de aprendizagem e os procedimentos metodológicos próprios a cada conteúdo. (KUENZER, 2010, p. 514).

Coaduna com Moura (2014), que afirma que a formação didáticopolítico-pedagógica é um dos núcleos estruturantes dos conhecimentos que devem estar presentes na formação do professor, pois além de trabalhar conhecimentos sobre currículo, avaliação, organização e planejamento da prática, também aborda as questões contextualizadas às especificidades que circunscrevem a EPT. Ou seja, considerando o trabalho e a educação, bem como as premissas que permeiam essa integração como ciência, cultura e relação com a sociedade.

Os dados também remetem a uma formação que aborde os conteúdos específicos, que são os conhecimentos adquiridos na formação inicial, proporcionando novos estudos e atualização dos saberes relacionados aos conteúdos ministrados em sala de aula. Para Moura (2014), a formação na área de conhecimentos específicos deve fazer parte do núcleo estruturante da formação do professor da educação profissional, tendo em vista a necessidade de ter competência técnica sobre a área de atuação, já que "[...] 
importa compreender que só se pode ensinar o que se domina em profundidade." (MOURA, 2014, p. 95).

Sobre o local para realizar a formação continuada, os dados indicam tanto para que aconteça na instituição quanto fora dela. Sobre a possibilidade de que aconteça na instituição, seria possível tanto porque o IFPE/Campus Recife oferece a estrutura adequada, quanto pela possibilidade de proporcionar a aproximação dos professores das diversas áreas.

Para Imbernón (2011), a formação continuada no local de trabalho do professor tem como meta principal um trabalho colaborativo que considera a própria prática, sendo possível "[...] aprender a interpretar, compreender e refletir sobre a educação e a realidade social de forma comunitária." (IMBERNÓN, 2011, p. 55).

Ter os professores indicando a escola como local da formação aponta para algo positivo, porém, a instituição não deve ser vista apenas como o espaço físico. É importante que o processo formativo consiga relacionar o conhecimento profissional ao contexto educativo, fazendo com que seja caracterizado por resolução e reflexão de problemáticas da prática. Essa seria uma maneira de reagir aos modelos tradicionais que apresentam atividades e metodologias para serem reproduzidas em sala de aula e passar a valorizar a realidade, as ideias e as crenças que permeiam a instituição, permitindo redefinir os conteúdos, os objetivos e a metodologia, de forma colaborativa entre os professores e formadores.

Por outro lado, também houve a indicação da formação que aconteça fora da instituição, remetendo para que os professores têm a necessidade de atualizar os conhecimentos e ter acesso a novos estudos em ambientes e formatos diversos como cursos, congressos e seminários.

Mas sobre esse aspecto, cabe frisar que a formação que aconteça fora da instituição é importante, mas não deve ser valorizada como única alternativa, pois o desenvolvimento de atividades elaboradas de forma fechada, sem considerar o contexto de trabalho, transforma o processo em mera atualização de informações científicas ou pedagógicas que podem não fazer sentido na prática. Como afirma Nóvoa (2002), como os problemas da prática não são meramente instrumentais, a racionalidade desvaloriza o saber docente ao impor novos conhecimentos.

Já em relação à metodologia, uma formação que permita a troca de experiência entre os professores surgiu nos dados, sendo justificada como espaço para ampliação do conhecimento por meio da socialização das práticas. Seria semelhante ao modelo "indagativo ou de pesquisa" citado por Imbernón (2011) como uma ferramenta de formação que tem como principal contribuição o fato de que, à medida que os professores trabalham juntos, cada um pode aprender com o outro, compartilhando evidências, informações e busca de soluções.

Candau (2001) afirma que o processo de formação continuada deve ter como referência fundamental o reconhecimento e a valorização do saber docente, de modo especial os saberes da experiência, a partir do qual o professor dialoga com as disciplinas e os saberes curriculares. Esses saberes experienciais são resultado do exercício da atividade profissional docente e 
incorporando-se sob a forma de habilidades, de saber-fazer e de saber ser. (TARDIF, 2014).

Oportunizar a troca de experiências na formação continuada pode propiciar a reflexão sobre a realidade e a partilha de saberes, consolidando espaços para a socialização de projetos e práticas como possibilidade de enaltecer o trabalho desenvolvido na instituição e a integração dos professores.

Uma formação que permita associar teoria e prática também foi apontada como importante, demonstrando necessidade de ser revisto o modelo que valoriza apenas a transmissão de conteúdos e sugerindo a adoção de estratégias de formação com base na ação. Coaduna com Imbernón (2011), quando afirma que uma formação que beneficie os professores deve trabalhar os conteúdos e explorar as atitudes; ser feita de forma interativa, refletindo no contexto sobre as situações reais; e ser experimentada, proporcionando a oportunidade para desenvolver uma prática reflexiva competente. Nesse sentido, a formação continuada deve ser pensada como superação da fragmentação entre teoria e prática, de forma que a prática encontre fundamentação nos conteúdos vivenciados durante 0 processo de formação, fazendo sentido para o trabalho docente.

Como formador, os dados remetem para que aconteça com mediador experiente, não importando se fosse alguém da instituição ou de fora dela, demonstrando o interesse dos professores por vivenciar momentos de aprendizagem que possam, de fato, contribuir para a formação profissional e consequente prática em sala de aula.

Imbernón (2011) se refere ao formador como o responsável por intervir a partir das demandas dos professores e instituições, com o objetivo de contribuir na resolução das problemáticas pertinentes à docência, num processo de compromisso de reflexão na ação. Seria, portanto, aquele com o papel mediador, para oferecer aos professores um "[...] conhecimento para que se apropriem e o interiorizem em um contexto determinado com uma finalidade de solução de situações práticas." (IMBERNÓN, 2011, p. 96).

Além de professores e pessoas de fora para mediar a formação, houve a indicação do pedagogo, o que pode acontecer em decorrência da própria especificidade da função, que é planejar e acompanhar a execução do processo de ensino-aprendizagem na instituição.

\footnotetext{
Quando se atribuem ao pedagogo as tarefas de coordenar e prestar assistência pedagógico-didática ao professor, não está se supondo que ele deva ter domínio dos conteúdos-métodos de todas as matérias. Sua contribuição vem dos campos do conhecimento implicados no processo educativo-docente, operando uma intersecção entre a teoria pedagógica e os conteúdos-métodos específicos de cada matéria de ensino, entre o conhecimento pedagógico e a sala de aula. (LIBÂNEO, 2007, p. 62).
}

Portanto, independente de ser professor, pedagogo ou pessoa de fora da instituição, importa que os formadores possam ter a capacidade de ser mobilizadores de conhecimentos de modo a conduzir os professores à construção de saberes necessários à prática. 
Considerando as expectativas dos sujeitos da pesquisa, pensar a formação continuada para os professores do EMI significa reestruturar o processo de forma a possibilitar o pertencimento a um espaço no qual seja possível trabalhar e adquirir conhecimento, aproximar as diferentes formações dos licenciados, bacharéis e tecnólogos, e ser instrumento para as práticas integradoras. O objetivo maior é que, por meio da formação continuada, os professores possam obter fundamentos para romper a fragmentação do ensino, ofertando uma formação que, de fato, seja integrada.

\section{CONSIDERAÇÕES FINAIS}

Os professores que atuam no EMI encontram uma modalidade na qual as inovações tecnológicas, exigências pertinentes ao mundo do trabalho, necessidade de qualidade na produção e serviços e maior atenção quanto às questões sociais, éticas e ambientais desafiam a formação.

Essas demandas, que refletem na construção e reestruturação dos saberes, exigem do professor conhecimentos de diferentes áreas como ciência, cultura e tecnologia, além daqueles relacionados ao processo de ensino, que envolve a definição de conteúdos, as metodologias e os instrumentos de avaliação.

A formação continuada seria, portanto, uma possibilidade para promover novos estudos e ressignificações, configurando-se como um processo que se efetiva mediada pela prática em sala de aula e envolve de forma complementar as seguintes dimensões: os princípios do EMI e a relação com o mundo do trabalho; a formação na área dos conhecimentos específicos para o domínio do conteúdo a ser ministrado; e a formação didático-político-pedagógica, necessária para a prática docente em sala de aula. Desse modo, colocamos a necessidade de instituir e implementar uma política de formação para os professores do EMI, elaborada a partir de fundamentos teóricos e metodológicos que contemplem a relação trabalho/educação, uma formação omnilateral e politécnica.

O desafio continua sendo a proposta de uma escola de qualidade para todos, ligada ao mundo econômico, tecnológico e cultural. Uma sociedade justa e inclusiva passa fundamentalmente pela escola, portanto, a formação do professor deve sempre ser considerada e valorizada.

\section{REFERÊNCIAS}

ARAÚJO, Ronaldo Marcos de Lima. Formação de professores para a educação profissional e tecnológica e a necessária atitude docente integradora. In: DALBEN, Ângela Imaculada Loureiro de Freitas. et al. (org.). Convergências e tensões no campo da formação e do trabalho docente. Belo Horizonte: Autêntica, 2010. p. 479-496.

BARDIN, Laurence. Análise de conteúdo. São Paulo: Edições 70, 2016. 
CANDAU, Vera Maria. Formação continuada de professores: tendências atuais. In: CANDAU, Vera Maria (org.). Magistério: construção cotidiana. 4. ed. Petrópolis: Vozes, 2001. p. 51-68.

CIAVATTA, Maria. A formação integrada: a escola e o trabalho como lugares de memória e identidade. Trabalho Necessário, Niterói, v. 3, n. 3, p. 01-20, 2005.

Disponível

em:

http://periodicos.uff.br/trabalhonecessario/issue/view/266. Acesso em: $21 \mathrm{dez}$. 2017.

FRIGOTTO, Gaudêncio. Concepções e mudanças no mundo do trabalho e o ensino médio. In: FRIGOTTO, Gaudêncio; CIAVATTA, Maria; RAMOS, Marise (orgs.). Ensino médio integrado: concepção e contradições. São Paulo: Cortez, 2005. p. 57-82.

GARCÍA, Carlos Marcelo. Formação de professores - para uma mudança educativa. Portugal: Porto Editora, 1999.

IMBERNÓN, Francisco. Formação docente e profissional: formar-se para a mudança e a incerteza. 9. ed. São Paulo: Cortez, 2011.

INSTITUTO FEDERAL DE EDUCAÇÃO, CIÊNCIA E TECNOLOGIA DE PERNAMBUCO. Edital no 44, de 25 de março 2014. Concurso público para professor de ensino básico, técnico e tecnológico. Recife: Reitoria, 2014. Disponível em: https://cvest.ifpe.edu.br/concurso2014_prof/arquivos/03EDITAL_N.44-2014-GR_ATUALIZADO_11_ABRIL_DE_2014-

PROFESSSOR.pdf. Acesso em: 12 out. $\overline{2} 01 \overline{8}$.

INSTITUTO FEDERAL DE EDUCAÇÃO, CIÊNCIA E TECNOLOGIA DE PERNAMBUCO. Edital no 67, de 14 de junho de 2017. Processo seletivo simplificado para professor substituto. Recife: Reitoria, 2017. Disponível em: https://cvest.ifpe.edu.br/selecao2017/arquivos/01\%20-

\%20Edital\%20n\%C2\%BA\%2067-2017-GR.pdf. Acesso em: 12 out. 2018.

INSTITUTO FEDERAL DE EDUCAÇÃO, CIÊNCIA E TECNOLOGIA DE PERNAMBUCO. Edital no 125, de 29 de agosto de 2016. Concurso público para professor de ensino básico, técnico e tecnológico. Recife: Reitoria, 2016. Disponível

em:

https://cvest.ifpe.edu.br/concurso2016_doc/arquivos/08.\%20Edital-125-2016GR\%20-\%20Retificado\%20em\%2018.01.2017\%20no\%20DOU.pdf. Acesso em: 12 out. 2018.

KUENZER, Acacia Zeneida. Formação de professores para a educação profissional e tecnológica. In: DALBEN, Ângela Imaculada Loureiro de Freitas. et al. (org.). Convergências e tensões no campo da formação e do trabalho docente. Belo Horizonte: Autêntica, 2010. p. 497-518.

LIBÂNEO, José Carlos. Pedagogia e pedagogos, para quê? 9. ed. São Paulo: Cortez, 2007. 
MACHADO, Lucília Regina de Souza. Diferenciais inovadores na formação de professores para a educação profissional. Revista Brasileira da Educação Profissional e Tecnológica, Brasília, v. 1, n. 1, p. 8-22, jun. 2008.

MOURA, Dante Henrique. A formação de docentes para a educação profissional e tecnológica. Revista Brasileira da Educação Profissional e Tecnológica, Brasília, v. 1, n. 1, p. 23-38, jun. 2008.

MOURA, Dante Henrique. Trabalho e formação docente na educação profissional. 1. ed. Curitiba: IFPR - EAD, 2014.

NÓVOA, António. Formação de professores e trabalho pedagógico. Lisboa: Educa, 2002.

RAMOS, Marise. Concepção do ensino médio integrado. 2008. Disponível em:

http://forumeja.org.br/go/sites/forumeja.org.br.go/files/concepcao_do_ensino_ medio_integrado5.pdf. Acesso em: 21 dez. 2017.

RAMOS, Marise N. Ensino médio integrado: lutas históricas e resistências em tempos de regressão. In: ARAÚJO, Adilson Cesar; SILVA, Cláudio Nei Nascimento da (orgs.). Ensino médio integrado no Brasil: fundamentos práticas e desafios. Brasília: Ed. IFB, 2017. p. 20-43.

SAVIANI, Dermeval. Trabalho e educação: fundamentos ontológicos e históricos. Revista Brasileira de Educação, Rio de Janeiro, v. 12, n. 32, p. 152-165, jan./abr. 2007. Disponível em: http://www.scielo.br/scielo.php?pid=S1413-

24782007000100012\&script=sci_abstract\&tlng=pt. Acesso em: 21 dez. 2017.

TARDIF, Maurice. Saberes docentes e formação profissional. 16. ed. Petrópolis: Vozes, 2014. 